\title{
TINJAUAN KEHILANGAN AIR PADA SALURAN PRIMER IRIGASI KAMPILI KABUPATEN GOWA
}

\author{
Muhammad Yunus Ali ${ }^{1)}$ Nurjannah $^{2)}$ dan Santi $^{3)}$ \\ ${ }^{1}$ Universitas Muhammadiyah Makassar, Indonesia \\ Email : Nurjannahjubram@gmail.com \\ ${ }^{2}$ Universitas Muhammadiyah Makassar, Indonesia \\ Email : $\underline{\text { Santiherman71@gmail.com }}$
}

\begin{abstract}
ABSTRAK
Efisiensi irigasi didefinisikan sebagai perbandingan antara jumlah air yang diberikan dikurangi kehilangan air dengan jumlah yang diberikan Penelitian ini bertujuan untuk mengetahui kehilangan air di saluran primer daerah irigasi kampili, serta menghitung nilai efisiensi penyaluran air pada saluran primer. Dengan menggunakan metode kuantitatif jenis penelitian secara langsung di lokasai dengan mengambil data yang di perlukan. Kehilangan air irigasi yang terjadi selama pemberian air disebabkan terutama oleh perembesan (seepage) di penampang basah saluran, evaporasi umumnya relatif kecil dan kehilangan operasional (operational losses) yang tergantung pada sistem pengelolaan air irigasi. Hasil penelitian yang telah dilakukan, diperoleh rata-rata nilai efisiensi sebesar 81,06 \% untuk saluran sepanjang 2.900 meter di Saluran Primer Kiri dan rata-rata sebesar 89,91\% untuk saluran sepanjang 900 meter di Saluran Sekunder, rata-rata sebesar 89,55\% untuk saluran sepanjang 900 meter di Saluran Sekunder Kampili. Berdasarkan studi ini efisiensi Jaringan Irigasi Kampili perlu ditingkatkan agar mencapai efisiensi yang ditetapkan dalam Kriteria Perencanaan Irigasi yaitu untuk Saluran Primer Efisiensinya $90 \%$ dan di Saluran Sekunder efisensinya $90 \%$.
\end{abstract}

Kata Kunci : Efisiensi, perembesan, evaporasi, kehilangan air

\begin{abstract}
The Efficiency of irrigation is defined as the ratio between the amount of water administered minus the water loss by the given amount. Loss of irrigation water that occurs during water delivery is mainly due topermeation in the wet channel cross section, evaporation is (generally relatively small) and operational losses dependent on irrigation water management system for irrigation. Water loss from tertiary tapping gates to rice field are commonly referred to as "tertiary delivery efficiencies", whereas the loss of water from tapping the weir to tertiary tapping is expressed as the efficiency of water delivery in the main network.The results of the efficiency analysis studies have obtained an average effiency rating of 81,06\% for the 2900 meter channel in the left primary channel and an average of 89,91\% ffor channels along 900 meters in the secondary channel, averaging 89,55\% for a 900 meter channel in the secondary Kampili.This type of research directly on site by taking the necessary data. Based on this study the efficiency of irrigation kampili network needs to be improved in order to achieve the efficiency set in the criteria of irrigation planning that is for the primary channel efficiency $90 \%$ and the secondary distribution efficiency $90 \%$.
\end{abstract}

Keywords : Evaporation, permeability, efficiency, of water loss 


\section{PENDAHULUAN}

Jaringan Irigasi yang baik untuk mempermudah dalam menunjang ketersediaan air yang lebih optimal.

$$
\text { Upaya peningkatan irigasi }
$$

membutuhkan penanganan tersendiri dalam suatu sistem perencanaan konfrehensif yakni bangunan irigasi dan ketersediaan air yang berlebih atau kurang sehingga distribusi air yang secara alami maupun rekayasa manusia, dapat terdistribusi dengan merata.

Daerah Jaringan Irigasi Kampili pertama kali di fungsikan pada tahun 2004 dan memiliki Jaringan Irigasi permukaan. Besarnya peningkatan tekanan pada sumber daya air yang tersedia untuk irigasi dan kebutuhan lainnya, terutama selama musim kemarau, membutuhkan Jaringan Irigasi yang memiliki efisiensi yang tinggi untuk menyalurkan air irigasi.

\section{Irigasi}

Irigasi berasal dari istilah irrigatie dalam bahasa Belanda atau irrigation dalam bahasa Inggris. Irigasi dapat pula diartikan sebagai suatu usaha yangdilakukan untuk mendatangkan air dari sumberdaya guna keperluan pertanian,mengalirkan dan membagikan air secara teratur dan setelah digunakan dapat pula di buang kembali. Istilah pengairan yang sering pula didengar dapat diartikan sebagai usaha pemanfaatan air pada umumnya, berarti irigasi termasuk di dalamnya.

Irigasi adalah suatu usaha untuk memprbaiki air guna keperluan pertanian yang dilakukan dengan tertib dan teratur untuk daerah pertanian yang dilakukan yang membutuhkannya dan kemudian air itu dipergunakan secara tertib dan teratur dibuang kesaluran pembuang. Istilanya irigasi diartikan suatu pembinaan atas air dari sumber-sumber air, termasuk kekayaan alami hewani yang terkandung didalamnya, baik yang alami maupun yang diusahakan manusia (Ambler, 1991).

Sudjarwadi(1987) mendefinisikan irigasi sebagai salah satu faktor penting dalam produksi bahan pangan. Sistem irigasi dapat diartikan sebagai satu kesatuan yang tersusun berbagai komponen, menyangkut upaya penyediaan, pembagian, pengelolaan dan pengaturan air dalam rangka meningkatkan produksi pertanian. Jaringan irigasi primer (saluran induk) yaitu saluran yang langsung berhubungan dengan saluran bendungan yang fungsinya untuk menyalurkan air dari waduk kesaluran yang lebih kecil. petak primer terdiri dari beberapa petak sekunder yang mengambil langsung air dari saluran primer.

\section{Kehilangan Air Irigasi}

Ada beberapa faktor yang mempengaruhi dalam memperkirakan 
kebutuhan air pengairan, diantaranya jenis dan sifat tanah, macam dan jenis tanaman, keadaan iklim, keadaan tofografi, luas areal pertanaman, kehilangan air selama penyaluran antara lain disebabkan oleh evaporasi, perkolasi, rembesan dan kebocoran saluran. terjadi kehilangn air (Winpenny, 1997), yaitu :

1) Di tingkat petani (farm level)

2) Pada tingkat jaringan (scheme)

3) Di tingkat daerah aliran sungai (basin)

Kehilangan air pada tiap ruas pengukuran debit masuk (Inflow) - debit keluar (Outflow) diperhitungkan sebagai selisih antara debit masuk dan debit keluar. Dan untuk itu dalam penelitian ini di perlukan Untuk persamaan yang sama kita bias lihat bagaimana rumus persamaan (Bunganaen W, 2011:3) $h n=I n-O n(1)$

Dimana :

$H n=$ kehilangan air pada ruas pengukuran/bentang saluran ke $\mathrm{n}$ (m3/det) In $=$ debit masuk ruas pengukuran ke $\mathrm{n}$ (m3/det)

$O n=$ debit keluar ruas pengukuran ke $n$ (m3/det)

Tolak ukur keberhasilan pengelolaan Jaringan Irigasi adalah efisiensi dan efektifitas. Efektifitas pengelolaan Jaringan Irigasi ditunjukkan oleh perbandingan antara luas areal terairi terhadap luas rancangan, juga dapat diartikan bahwa irigasi yang dikelola secara efektif mampu mengairi areal sawah sesuai dengan yang diharapkan. Dalam hal ini tingkat efektifitas ditunjukkan oleh indeks luas area (Ramadhan F, 2013:27).

IndeksLuasAreali $=$

$\frac{\text { Luas Areal Terairi }}{\text { Luas Rancangan }}$ X $100 \%$

\section{Definisi Efisiensi Irigasi}

Menurut Sudjawardi

$(1987: 30)$

efisiensi irigasi adalah pemanfaatan air untuk tanaman, yang di ambil dari sumber air atau sungai yang di alirkan ke areal irigasi melalui bendung. Secara kuantitatif efisiensi irigasi suatu jaringan irigasi sangat kurang diketahui dan merupakan parameter yang sukar diukur. Akan tetapi sangat penting dan umumnya diasumsikan untuk menambah $40 \%$ sampai $100 \%$ terhadap keperluan air irigasi di bendung. Kehilangan air irigasi pada tanaman padi berhubungan dengan : (a) kehilangan air di saluran primer, sekunder dan tersier melalui rembesan, evaporasi, pengambilan air tanpa ijin dan lain-lain, (b) kehilangan akibat pengoperasian termasuk pemberian air yang berlebihan. pengaturan dan air irigasi merupakan sesuatu tanaman padi.

\section{Efisiensi Pemakaian Air}

Efisiensi pemakaian air (application efficiency) di sawah EPA adalah perbandingan antara jumlah air irigasi yang 
diperlukan tanaman (Vn) dengan jumlah air yang sampai ke suatu inlet jalur atau petakan sawah (Vsw). Jumlah air irigasi yang diperlukan tanaman disebut dengan $\mathrm{V}$ netto adalah jumlah air yang diperlukan tanaman (W) dikurangi dengan hujan efektif (He). Untuk padi sawah nilai $\mathrm{W}$ adalah perjumlahan dari nila nilai ET, Perkolasi, dan Genangan. Untuk suatu rehabilitas sebagai penentu baik.

Efisiensi irigasi menunjukkan angka daya guna pemakaian air yaitu merupakan perbandingan antara jumlah air yang digunakan dengan jumlah airyang diberikan yang dinyatakan dalam persen $(\%)$.

Efisiensi $=$ $\frac{\text { Debit air yang keluar }\left(m^{3} / d t\right)}{\text { Debit air yang masuk }\left(m^{3} / d t\right)} \times 100 \%$

Bila angka kehilangan air naik maka efisiensi akan turun dan begitu pula sebaliknya. Efiesiensi diperlukan karena adanya pengaruh kehilangan air yang disebabkan oleh evaporasi, perkolasi, infiltrasi, kebocoran dan rembesan. Perkiraan efisiensi irigasi ditetapkan sebagai berikut (KP-01, 1986: 10) : (1) jaringan tersier $=80 \%$; (2) jaringan sekunder $=90 \%$; dan $(3)$ jaringan primer $=$ $90 \%$. Sedangkan faktor efisiensi irigasi secara keseluruhan adalah $80 \%$ x $90 \%$ x $90 \%=65 \%$.

\section{Penghematan Air Di Jaringan Distribusi}

Efisiensi penyaluran air merupakan tahap awal dari konsep efisiensi Irigasi untuk menghitung kehilangan air. Setelah air sampai di areal pertanian, maka muncul masalah pemakain air secara efisien. Jumlah air yang diberikan pada areal pertanian biasanya lebih besar dari kemampuan

\section{Kriteria Efisiensi Pengairan}

Efisiensi pengairan yang pada umumnya terjadi di jaringan utama dan efisiensi di jaringan sekunder yaitu dari bangunan pembagi sampai petak sawah, Efisiensi irigasi didasarkan asumsi sebagian dari jumlah air yang diambil akan hilang baik di saluran maupun di petak sawah. Kehilangan air yang diperhitungkan untuk operasi irigasi meliputi kehilangan air di tingkat tersier, sekunder dan primer. Besarnya masing-masing kehilangan air tersebut dipengaruhi oleh panjang saluran, luas permukaan saluran, keliling basah saluran dan kedudukan air tanah.

\section{METODE PENELITIAN}

\section{Lokasi dan Waktu Penelitian}

Daerah Irigasi Kampili terletak di desa Kampili Kecamatan Pallangga Kabupaten Gowa. Daerah tersebut secara terletak pada titik koordinat $05^{\circ} 16^{\prime}$ LS 119³0' BT, lokasi penelitian dapat dilihat pada lampiran1. Daerah Irigasi Kampili mendapat suplai air dari Bendungan Kampili, yang terletak pada titik koordinat 
05¹6' LS - 119³1' BT Penelitian ini dilakukan di Daerah Jaringan Irigasi Kampili Kabupaten Gowa dimulai bulan Desember 2017 sampai bulan April 2018.

\section{Jenis Penelitian dan Sumber Data}

Jenis penelitian ini menggunakan penelitian secara langsung di lokasi dengan mengambil data yang diperlukan dalam penelitian ini. Seperti pada flow cart di bawah ini

Flow Chart/Bagan Alur Penelitian

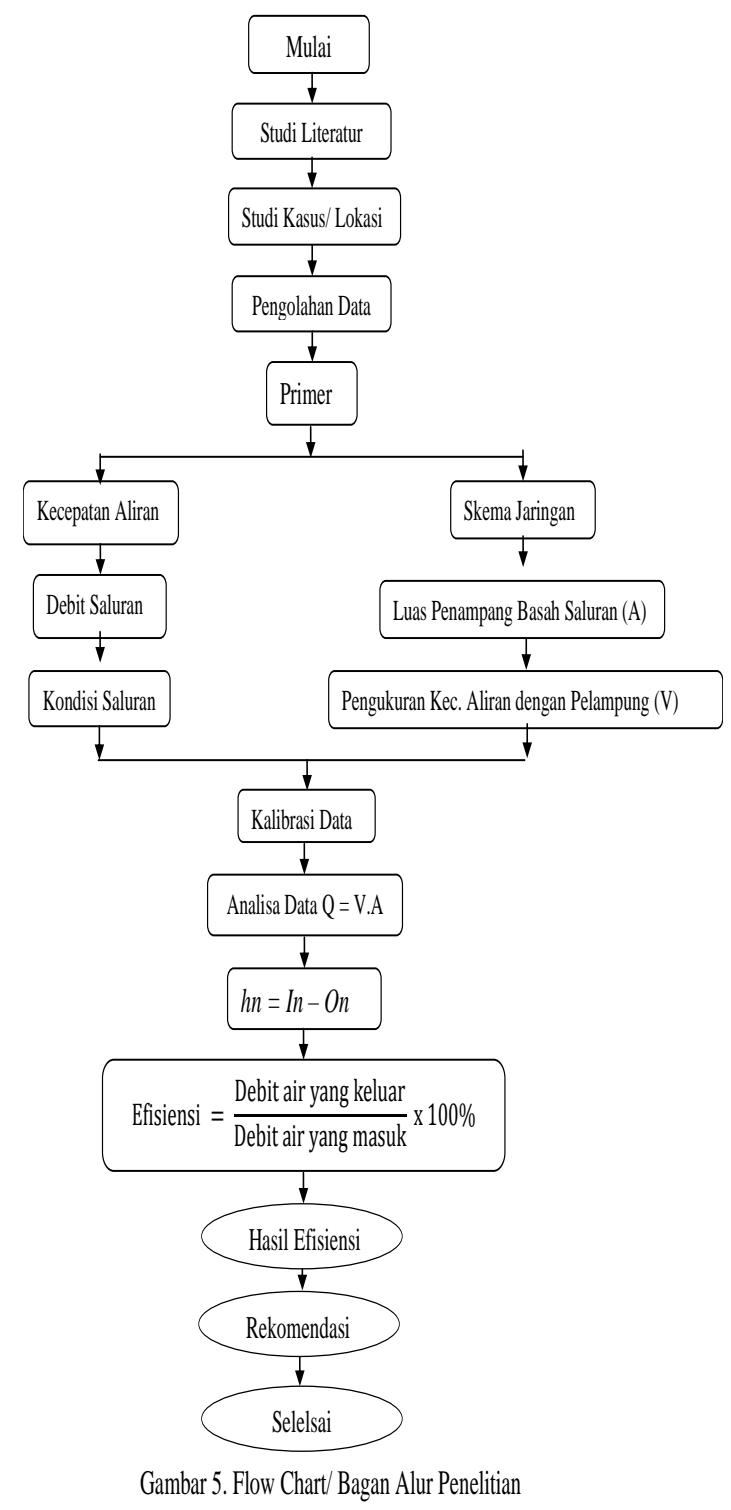

\section{HASIL DAN PEMBAHASAN}

\section{Hasil Penelitian}

Hasil penelitian yang diperoleh melalui pengukuran kecepatan aliran pada keadaan diatas muka air normal, yang dapat diteliti dan diamati dengan cara manual yaitu melepaskan bola pimpong diatas permukaan aliran dan mencatat waktu yang diperlukan oleh bola pimpong, dalam menempuh jarak 100 meter. Pada pengukuran kecepatan dilakukan pada tinggi muka air 2,00 meter, 1,97 meter, 1,59 meter, 1,55 meter, 1,50 meter.

\section{Pengukuran Aliran permukaan dengan}

\section{Pelampung}

1) Untuk data Hulu Saluran Induk BL.0BL.1dengan panjang lintasan pelampung $(\mathrm{L})=100$ meter, waktu lintasan rata-rata $(\mathrm{T})=11,87 \mathrm{dtk}$ ratarata tinggi muka air $(\mathrm{H})=2$ meter.

2) Hitung Kecepatan Aliran dengan menggunakan rumus

Dimana $: \mathrm{Vp}=\frac{\mathrm{D}}{\mathrm{T}}=\frac{100}{12,22}=$ $7,67 \mathrm{~m} / \mathrm{dtk}$.

Dan untuk koefisien pelampung

Dimana Vs $=\alpha \times \mathrm{V}=0,91 \times 8,42=$ $7,67 \mathrm{~m} / \mathrm{dt}$.

\section{Perhitungan Debit Aliran}

Berdasarkan data pengukuran pelampung, maka dapat di hitung 
debit aliran pada ruas BL.0 - BL.1 (Hulu) dalam kondisi diatas muka air normal dengan rumus :

$\mathrm{Q}=(\mathrm{A} \times \mathrm{V})$

dimana ; Kecepatan Aliran (V) $=7,67$ meter, Lebar saluran $(b)=10,75$ meter, Tinggi permukaan air $(\mathrm{h})=2$ meter, Kemiringan saluran $(\mathrm{m})=1$, Luas penampang basah $(\mathrm{A})=(\mathrm{b}+\mathrm{mh}) \mathrm{h}=$ $(10,75+2 \times 1)=12,75$ meter $^{2}$ Debit air $(\mathrm{Q})=12,75 \times 7,67=241,56 \mathrm{~m}^{3} / \mathrm{dtk}$.

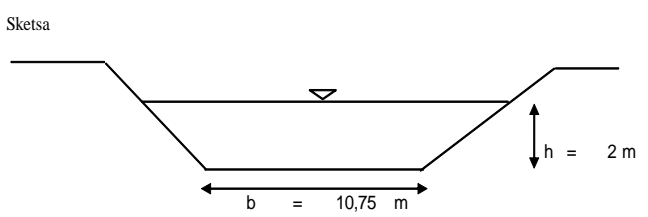

Gambar 2. Dimensi Saluran

Tabel 1.Pengamatan Percobaan Dengan Alat Pelampung Untuk Daerah Hulu

\begin{tabular}{|c|c|c|c|c|c|c|c|c|c|c|}
\hline \multirow{3}{*}{ N0 } & \multirow{3}{*}{ Lokasi } & \multicolumn{6}{|c|}{ Waktu Tempuh } & \multirow{3}{*}{$\begin{array}{l}\text { - Trataratata } \\
\text { Hulu Hilir } \\
\end{array}$} & \multicolumn{2}{|c|}{ Kecepatan Aliriman (m/dtk) } \\
\hline & & \multicolumn{3}{|c|}{ Hulu } & \multicolumn{3}{|c|}{ Hiliir } & & \multirow{2}{*}{$\begin{array}{c}\text { Hulu } \\
V_{p}=L / T \\
\end{array}$} & \multirow{2}{*}{$\begin{array}{c}\text { Hilir } \\
V_{p}=L / I \\
\end{array}$} \\
\hline & & $\mathrm{T1}$ & T2 & 13 & $\mathrm{T1}$ & T2 & $\mathrm{T3}$ & & & \\
\hline 1 & BLO-BLl & 12 & 11.58 & 12.02 & 12.23 & 12.19 & 12.25 & $11.87 \quad 12.22$ & 8.43 & 8.18 \\
\hline 2 & BLI-BL2 & 12.30 & 12.29 & 12.34 & 12.40 & 12.42 & 14,39 & 12.3113 .07 & 8.12 & 7.65 \\
\hline 3 & BL2-BL3 & 13.05 & 13.03 & 13.03 & 13.36 & 13.34 & 13.39 & $13.04 \quad 13.36$ & 7.67 & 7.48 \\
\hline 4 & BL3-BLA & 14.08 & 14.06 & 14.10 & 14.25 & 14.23 & 14.27 & $14.08 \quad 14.25$ & 7.10 & 7.02 \\
\hline 5 & BLA-BL5 & 14.20 & 14.18 & 14.24 & 14.40 & 14.38 & 14.41 & $14.21 \quad 14.40$ & 7.04 & 6.95 \\
\hline 6 & $B L 5 \cdot B L 6$ & 13.35 & 13.32 & 13.36 & 13.53 & 13.52 & 13.55 & $13.34 \quad 13.53$ & 7.49 & 7.39 \\
\hline 7 & BL6-BL7 & 13.00 & 12.58 & 13.02 & 13.30 & 13.28 & 13,31 & 12.8713 .30 & 7.77 & 7.52 \\
\hline 8 & BL7-BL8 & 14.30 & 14.31 & 14.29 & 14.48 & 14.46 & 14.49 & 14.3014 .48 & 6.99 & 6.91 \\
\hline 9 & BL8-BL9 & 15.10 & 15.09 & 15.13 & 15.35 & 15.33 & 15.37 & $15.11 \quad 15.35$ & 6.62 & 6.51 \\
\hline 10 & BL9. BLL10 & 15.08 & 15.06 & 15.12 & 15.25 & 15.23 & 15.27 & 15.0915 .25 & 6.63 & 6.56 \\
\hline 11 & BLIO-BLII & 14.48 & 14.46 & 15.00 & 15.05 & 15.03 & 15.08 & $\begin{array}{lll}14.65 & 15.05 \\
\end{array}$ & 6.83 & 6.64 \\
\hline 12 & BLI1-BL12 & 14.20 & 14.18 & 14.20 & 14.43 & 14.40 & 14.4 & $14.19 \quad 14.42$ & 7.05 & 6.93 \\
\hline 13 & BLI2-BL13 & 14.05 & 14.02 & 13.02 & 14.30 & 14.27 & 14.31 & 13.7014 .29 & 7.30 & 7.00 \\
\hline 14 & BLL3-BLIA & 13.00 & 12.57 & 13.02 & 13.10 & 13.09 & 13.13 & 12.8613 .11 & 7.77 & 7.63 \\
\hline 15 & BLLA-BLL5 & 14.21 & 14.00 & 14.18 & 14.32 & 14.25 & 14.33 & $\begin{array}{lll}14.13 & 14.30 \\
\end{array}$ & 7.08 & 6.99 \\
\hline 16 & BLL5-BL16 & 13.15 & 13.13 & 13.16 & 13.30 & 13.28 & 13.32 & $13.15 \quad 13.30$ & 7.61 & 7.52 \\
\hline 17 & BLI6-BLI7 & 12.17 & 12.15 & 12.20 & 12.37 & 12.35 & 12.40 & $12.17 \quad 12.37$ & 8.21 & 8.08 \\
\hline
\end{tabular}

Pengukuran yang dilaksanakan dilapangan yang di mulai dari saluran Kampili (BL.0) sampai dengan saluran Bontolangkasa (BL.17) dilaksanakan selama satu minggu lamanya pada tanggal 17 Desember pukul 09:11 - 14:18, sampai tanggal 23 Desember pukul 10:08.

Dari perhitungan di atas di dapatkan nilai waktu tempuh pelampung (T) dimana pengukuran kecepatannya di bagi tiga titik yaitu titik a (T1), titik b (T2) dan titk c (T3), waktu pelepasan pelampung di mulai pada saat melewati garis titik yang sudah di tentukan dan perhitungan waktu lintasan pelampung menggunakan stopwatch. Dan untuk $\mathrm{T}$ rata-rata di dapatkan dari hasil pembagian T1, T2, dan T3.

Nilai kecepatan arus permukaan (Vp) diperoleh dari jarak lintasan pelampung (L) di bagi dengan waktu tempuh pelampung $(\mathrm{T})$, dan untuk nilai kecepatan aliran (V) yang diperoleh dari kecepatan arus permukaan (Vp) di kali dengan kondisi air normal (K). Dan untuk hasil yang memungkinkan diperlukan penelitian yang lebih lanjut dan pasti. Pengukuran ini dapat dilakukan di bagian mana yang ditempatkan sebagai acuan penelitian sebagai proses yang diharapkan. Sebagaimana yang kami lihat dari telah diterangkan dalam penelitian ini diatas.

Tabel 2.Hasil perhitungan debit air dengan metode pelampung untuk Daerah Hulu 


\begin{tabular}{|c|c|c|c|c|c|c|c|c|c|c|}
\hline \multirow{2}{*}{10} & \multirow{2}{*}{ Lokasi } & \multicolumn{3}{|c|}{ Jarak Pengukuran } & \multicolumn{3}{|c|}{ Data Saluran } & \multicolumn{3}{|c|}{ Hitungan } \\
\hline & & JU.I & JU.II & JU.III & $b(\mathrm{~m})$ & $h(\mathrm{~m})$ & $\mathrm{m}$ & $A\left(\mathrm{~m}^{2}\right)$ & $V$ (m/dtk) & $Q\left(\mathrm{~m}^{3} / \mathrm{dtk}\right)$ \\
\hline 1 & 2 & 3 & 4 & 5 & 1 & 9 & 10 & 11 & 12 & 13 \\
\hline 1 & BLO-BLI & 100.00 & 100.00 & 100.00 & 10.75 & 2.00 & 1.00 & 25.50 & 7.67 & 195.55 \\
\hline 2 & BLI - BL2 & 100,00 & 100.00 & 10000 & 10.75 & 2.00 & 1.00 & 25.50 & 7.39 & 188.51 \\
\hline 3 & $B L 2 \cdot B L 3$ & 10000 & 100.00 & 100.00 & 11.00 & 1.97 & 1.00 & 25.55 & 6.98 & 177.35 \\
\hline 4 & BL3-BLA & 10000 & 100.00 & 100.00 & 10.70 & 1.97 & 1.00 & 24.96 & 6.46 & 161.32 \\
\hline 5 & BLA-BL5 & 100,00 & 100.00 & 100,00 & 10.70 & 1.96 & 1.00 & 24.81 & 6.40 & 158.92 \\
\hline 6 & BL5. BL6 & 100,00 & 100.00 & 100.00 & 10.70 & 1.96 & 1.00 & 24.81 & 6.82 & 169.23 \\
\hline 7 & BL6-BL7 & 100000 & 100.00 & 100.00 & 11.25 & 1.59 & 1.5 & 21.68 & 7.10 & 153.86 \\
\hline 8 & BL7-BL8 & 100,00 & 100.00 & 100.00 & 11.25 & 1.59 & 1.5 & 21.68 & 6.36 & 137.96 \\
\hline 9 & BL8-BL9 & 100000 & 100.00 & 10000 & 11.25 & 1.59 & 1.5 & 21.68 & 6.02 & 130.58 \\
\hline 10 & BL9. BL10 & 100,00 & 100.00 & 100,00 & 11.50 & 1.56 & 1.5 & 21.59 & 6.03 & 130.21 \\
\hline 11 & BL10-BLL11 & 100,00 & 100.00 & 100.00 & 11.50 & 1.55 & 1.5 & 21.43 & 6.19 & 132.63 \\
\hline 12 & BLI1-BLLI2 & 100,00 & 100.00 & 100,00 & 11.50 & 1.55 & 1.5 & 21.43 & 6.41 & 137.41 \\
\hline 13 & BLI2-BL13 & 100,00 & 100.00 & 100.00 & 7.70 & 1.58 & 1.5 & 15.91 & 6.67 & 106.09 \\
\hline 14 & BL13-BLL14 & 100000 & 100.00 & 100.00 & 5.50 & 1.50 & 1.5 & 11.63 & 7.10 & 82.53 \\
\hline 15 & BL14-BLL5 & 100,00 & 100.00 & 100.00 & 5.50 & 1.50 & 1.5 & 11.63 & 6.63 & 77.10 \\
\hline 16 & BL15. BLI6 & 100000 & 100.00 & 100000 & 6.50 & 1.39 & 1.5 & 11.93 & 6.95 & 82.94 \\
\hline 17 & BL16-BL17 & 100000 & 100.00 & 100000 & 5.50 & 1.32 & 1.5 & 9.87 & 8.21 & 81.10 \\
\hline
\end{tabular}

Untuk perhitungan di atas menghasilkan hasil efisiensi dari pengukuran di lapangan dimana kehilangan air banyak terjadi pada saluran BL.1-BL.213,54 $\mathrm{m}^{3} / \mathrm{dtkdan}$ efisiensinya BL.1-BL.297,08\%.

Melihat hasil analisis perhitungan pengukuran di lapangan, saluran Irigasi Kampili sudah memenuhi kriteria efisiensi saluran karena, kehilangan air yang terjadi sepanjang saluran induk Kampili rata-rata 97,30\% sedangkan perkiraan efisiensi irigasi dalam (KP-01, 1986: 10 : 1) yaitu pada jaringan primer $90 \%$.

Tabel 3.Perhitungan efisiensi kehilangan air pada saluran Induk Kampili untuk Daerah Hulu

\begin{tabular}{|c|c|c|c|c|c|c|c|c|c|c|}
\hline \multirow{3}{*}{ No } & \multirow{3}{*}{ Lokasi } & \multicolumn{6}{|c|}{ Waktu Tempuh } & & \multicolumn{2}{|c|}{ Kecepatan Aliran (modtlk) } \\
\hline & & \multicolumn{3}{|c|}{ Hulu } & \multicolumn{3}{|c|}{ Hiliir } & & Hulu & \multirow{2}{*}{$\begin{array}{c}\text { Hiliri } \\
I_{p}=L / T\end{array}$} \\
\hline & & $\mathrm{T1}$ & $\mathrm{T} 2$ & 13 & $\mathrm{T1}$ & $\mathrm{T} 2$ & $T 3$ & Hulu Hilir & $V_{p}=L / T$ & \\
\hline 1 & BLO-BLI & 12 & 11.58 & 12.02 & 12.23 & 12.19 & 12.25 & 611.8712 .22 & 8.43 & 8.18 \\
\hline 2 & BLI-BL2 & 12,30 & 12.29 & 12.34 & 12.40 & 12.42 & 1439 & 12.3113 .07 & 8.12 & 7.65 \\
\hline 3 & BL2-BL3 & 13.05 & 13.03 & 13.03 & 13.36 & 13.34 & 13.39 & 13.0413 .36 & 7.67 & 7.48 \\
\hline 4 & BL3-BLA & 14,08 & 14.06 & 14.10 & 14.25 & 14.23 & 14.27 & 14.0814 .25 & 7.10 & 7.02 \\
\hline 5 & BLA-BL5 & 14,20 & 14.18 & 14.24 & 14,40 & 14,38 & 1441 & $14.2114,40$ & 7.04 & 6.95 \\
\hline 6 & BL5-BL6 & 13,35 & 13.32 & 13.36 & 13.53 & 13.52 & 13.55 & 613.3413 .53 & 7.49 & 7.39 \\
\hline 7 & BL6-BL7 & 13,00 & 12.58 & 13.02 & 13,30 & 13.28 & 13.31 & 12.8713 .30 & 7.77 & 7.52 \\
\hline 8 & BL7-BL8 & 14,30 & 1431 & 14.29 & 14.48 & 1446 & 14.49 & 14.3014 .48 & 6.99 & 6.91 \\
\hline 9 & BL\&-BL9 & 15,10 & 15.09 & 15.13 & 15.35 & 15.33 & 15.37 & 15.1115 .35 & 6.62 & 6.51 \\
\hline 10 & BL9-BLLO & 15.08 & 15.06 & 15.12 & 15.25 & 15.23 & 15.27 & 15.0915 .25 & 6.63 & 6.56 \\
\hline 11 & BLLO-BLII & 14.48 & 14.46 & 15.00 & 15.05 & 15.03 & 15.08 & 14.6515 .05 & 6.83 & 6.64 \\
\hline 12 & BLL1-BLI2 & 14.20 & 14.18 & 14.20 & 14.43 & 1440 & 1444 & 414.1914 .42 & 7.05 & 6.93 \\
\hline 13 & BLL2-BL13 & 14.05 & 14.02 & 13.02 & 14,30 & 14.27 & 14,31 & 13.7014 .29 & 7.30 & 7.00 \\
\hline 14 & BLL3-BLLA & 13.00 & 12.57 & 13.02 & 13,10 & 13.09 & 13.13 & 312.8613 .11 & 7.77 & 7.63 \\
\hline 15 & ZLLA-BLL15 & 14,21 & 14,00 & 14.18 & 14,32 & 14.25 & 14.33 & $14.1314,30$ & 7.08 & 6.99 \\
\hline 16 & LL15-BLL16 & 13.15 & 13.13 & 13.16 & 13.30 & 13.28 & 13.32 & 23.1513 .30 & 7.61 & 7.52 \\
\hline 17 & BLL6-BL17 & 12,17 & 12.15 & 12.20 & 12.37 & 12.35 & 12.40 & 12.1712 .37 & 8.21 & 8.08 \\
\hline
\end{tabular}

Tetapi kami selaku peneliti tidak bisa memastikan hal ini karena, selama penelitian ini dilaksanakan mungkin saja terjadi kesalahan pada proses perhitungan kecepatan aliran terutama pada lintasan pelampung. karena mengingat pelaksanaan pengukuran ini bertepatan dengan musim hujan yang sangat mempengaruhi kecepatan lintasan pelampung dan mengingat tingginya debit air yang membuat kecepatan pelampung bertambah. Untuk penelitian ini dibutuhkan konsentrasi yang lebih Pasti dan memungkinkang untuk anda.

Tabel 4.Hasil perhitungan debit air dengan metode pelampung untuk Daerah Hilir 


\begin{tabular}{|c|c|c|c|c|c|c|c|c|c|c|}
\hline \multirow{2}{*}{10} & \multirow{2}{*}{ Lokasi } & \multicolumn{3}{|c|}{ Jarak Pengukuran } & \multicolumn{3}{|c|}{ Data Saluran } & \multicolumn{3}{|c|}{ Hitungan } \\
\hline & & JU.I & JU.II & JU.III & $b(m)$ & $\mathrm{h}(\mathrm{m})$ & $\mathrm{m}$ & $A\left(\mathrm{~m}^{2}\right)$ & $V$ (m/dtk) & $Q\left(\mathrm{~m}^{3} / \mathrm{dtk}\right)$ \\
\hline 1 & 2 & 3 & 4 & 5 & 1 & 9 & 10 & 11 & 12 & 13 \\
\hline 1 & BLO-BLI & 100.00 & 100.00 & 100.00 & 10.75 & 2.00 & 1.00 & 25.50 & 7.67 & 195.55 \\
\hline 2 & BLI-BL2 & 100,00 & 100.00 & 100.00 & 10.75 & 2.00 & 1.00 & 25.50 & 7.39 & 188.51 \\
\hline 3 & $\mathrm{BL} 2 \cdot \mathrm{BL} 3$ & 100.00 & 100.00 & 100.00 & 11.00 & 1.97 & 1.00 & 25.55 & 6.98 & 178.35 \\
\hline- & $B L 3-B L A$ & 100.00 & 100.00 & 100.00 & 10.70 & 1.97 & 1.00 & 24.96 & 6.46 & 161.32 \\
\hline 5 & BLA-BL5 & 100.00 & 100.00 & 100.00 & 10.70 & 1.96 & 1.00 & 24.81 & 6.40 & 158.92 \\
\hline 6 & BL5-BL6 & 100.00 & 100.00 & 100.00 & 10.70 & 1.96 & 1.00 & 24.81 & 6.82 & 169.23 \\
\hline 1 & BL6-BL7 & 100.00 & 100.00 & 100.00 & 11.25 & 1.59 & 1.5 & 21.68 & 7.10 & 153.86 \\
\hline 8 & BL7-BL8 & 100.00 & 100.00 & 100.00 & 11.25 & 1.59 & 1.5 & 21.68 & 6.36 & 137.96 \\
\hline 9 & BL\&-BL9 & 100,00 & 100.00 & 100.00 & 11.25 & 1.59 & 1.5 & 21.68 & 6.02 & 130.58 \\
\hline 10 & BL9-BL10 & 100.00 & 100.00 & 100.00 & 11.50 & 1.56 & 1.5 & 21.59 & 6.03 & 130.21 \\
\hline 11 & BLL10-BLII & 100.00 & 100.00 & 100.00 & 11.50 & 1.55 & 1.5 & 21.43 & 6.19 & 132.63 \\
\hline 12 & BLL11-BLI2 & 100.00 & 100.00 & 100.00 & 11.50 & 1.55 & 1.5 & 21.43 & 6.41 & 137.41 \\
\hline 13 & BLL2-BL13 & 100,00 & 100.00 & 100.00 & 7.70 & 1.58 & 1.5 & 15.91 & 6.67 & 106.09 \\
\hline 14 & BLL13-BL14 & 100,00 & 100.00 & 100.00 & 5.50 & 1.50 & 1.5 & 11.63 & 7.10 & 82.53 \\
\hline 15 & BLL14-BLL15 & 100.00 & 100.00 & 100.00 & 5.50 & 1.50 & 1.5 & 11.63 & 6.63 & 77.10 \\
\hline 16 & BL15-BL16 & 100.00 & 100.00 & 100.00 & 6.50 & 1.39 & 1.5 & 11.93 & 6.95 & 82.94 \\
\hline 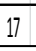 & BLL16-BL17 & 100.00 & 100.00 & 100.00 & 5.50 & 1.32 & 1.5 & 9.87 & 8.21 & 81.10 \\
\hline
\end{tabular}

\section{Analisis Efisiensi}

Berdasarkan data pengukuran pelampung di atas, maka dapat di hitung kehilangan air pada saluran induk Kampili pada ruas BL0-BL1 dengan rumus:

$\mathrm{hn}=\mathrm{In}-\mathrm{On}$

Dimana ; Debit Hulu $=241,56 \mathrm{~m}^{3} / \mathrm{dtk}$, Debit Hilir $=234,51 \mathrm{~m}^{3} / \mathrm{dtk}=241,56-$ $234,51=7,05 \mathrm{~m}^{3} /$ dtkSedangkan untuk efisiensi saluran induk Kampili dapat dilihat sebagaimana rumus dan perhitungan yang ditentukan sesuai dengan apa yang diharapkan dan juga apa yang dalam rumus di bawah ini sebagaimana yang diharapkan dihitung dengan rumus :

Efisiensi $=\frac{\text { Debit air yang keluar }\left(\mathrm{m}^{3} / \mathrm{dt}\right)}{\text { Debit air yang masuk }\left(\mathrm{m}^{3} / \mathrm{dt}\right)} \times 100 \%$

Maka Efisiensi Penyaluran :

$$
\mathrm{Ep}=\frac{\text { Debit air yang keluar }}{\text { debit air yang masuk }} \times 100 \%
$$

$$
\begin{aligned}
\text { Ep } & =\frac{241,56}{234,51} \times 100 \% \\
& =97,68 \%
\end{aligned}
$$

Perhitungan kehilangan dan efisiensi daerah hulu dan hilir saluran Induk Kampili menunjukkan kehilangan air yang terjadi pada ruas BL.0-BL.1 yaitu 7,05\% dan efisiensinya $97,68 \%$.

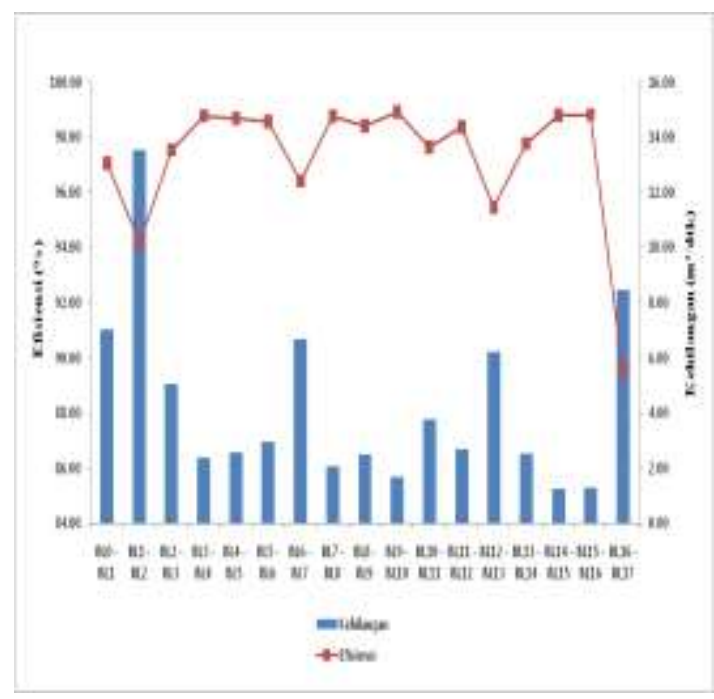

Gambar 3. grafik hubungan titik pengamatan dengan kehilangan air dan efisiensi penyaluran pada setiap ruas saluran hulu dan hilir.

Untuk grafik di atas menunjukkan hasil efisiensi dari pengukuran di lapangan dimana kehilangan air banyak terjadi pada saluran BL.1-BL.2yaitu 7,05 m³/dtk dan efisiensinya $94,14 \%$. Sedangkan kehilangan air paling kecil terjadi pada saluran BL.16-BL.17 yaitu 8,49 m³/dtk dan efisiensinya yaitu $89,94 \%$.

Tabel 5.Perhitungan efisiensi kehilangan air pada saluran Induk Kampili untuk Daerah hilir 


\begin{tabular}{|c|c|c|c|c|c|c|c|c|}
\hline \multirow{2}{*}{ No } & \multirow{2}{*}{ Pengukuran } & \multicolumn{3}{|c|}{ Jarak Pengukuran } & \multicolumn{2}{|c|}{ Debit ( $\left.\mathrm{m}^{3} / \mathrm{dtk}\right)$} & \multirow{2}{*}{$\begin{array}{c}\text { Kehilangan } \\
(\mathrm{m} / \mathrm{d})\end{array}$} & \multirow{2}{*}{$\begin{array}{c}\text { Ehlisiensi } \\
(\%)\end{array}$} \\
\hline & & JU.I & JU.II & JU.III & Hulu & Hilir & & \\
\hline 1 & BLO-BLI & 100.00 & 100.00 & 100.00 & 195.55 & 189.84 & 5.71 & 97.08 \\
\hline 2 & BL1-BL2 & 100.00 & 100.00 & 100.00 & 188.51 & 177.54 & 10.96 & 94.19 \\
\hline 3 & $B L 2-B L 3$ & 100.00 & 100.00 & 100.00 & 178.35 & 173.993 & 4.36 & 97.56 \\
\hline 4 & $B 13 \cdot B L 4$ & 100.00 & 100.00 & 100.00 & 161.32 & 159.393 & 1.92 & 98.81 \\
\hline 5 & BLL-BLL & 100.00 & 100.00 & 100.00 & 158.92 & 156.844 & 2.07 & 98.70 \\
\hline 6 & $B 15 \cdot B 16$ & 100.00 & 100.00 & 100.00 & 169.23 & 166.850 & 2.38 & 98.60 \\
\hline 7 & BL6-BL7 & 100.00 & 100.00 & 100.00 & 153.86 & 148.37 & 5.49 & 96.43 \\
\hline 8 & BL7-B18 & 100.00 & 100.00 & 100.00 & 137.96 & 136.28 & 1.68 & 98.78 \\
\hline 9 & BL8-BLG & 100.00 & 100.00 & 100.00 & 130.58 & 128.52 & 2.05 & 98.43 \\
\hline 10 & BLI-BL1O & 100.00 & 100.00 & 100.00 & 130.21 & 128.835 & 1.38 & 98.94 \\
\hline 11 & BL10-BL11 & 100.00 & 100.00 & 100.00 & 132.63 & 129.540 & 3.09 & 97.67 \\
\hline 12 & BL11-BL12 & 100.00 & 100.00 & 100.00 & 137.41 & 135.199 & 2.21 & 98.39 \\
\hline 13 & BL12-BL13 & 100.00 & 100.00 & 100.00 & 106.09 & 101.296 & 4.79 & 95.48 \\
\hline 14 & BL13-BL14 & 100.00 & 100.00 & 100.00 & 82.53 & 80.713 & 1.82 & 97.80 \\
\hline 15 & BL14-BL15 & 100.00 & 100.00 & 100.00 & 77.10 & 73.977 & 3.13 & 95.94 \\
\hline 16 & BL15-BL16 & 100.00 & 100.00 & 100.00 & 82.94 & 76.611 & 6.32 & 92.37 \\
\hline 17 & BL16-B1.17 & 100.00 & 100.00 & 100.00 & 81.10 & 72.616 & 8.49 & 89.54 \\
\hline \multicolumn{7}{|c|}{ RATA-RATA } & 3.99 & 96.75 \\
\hline
\end{tabular}

Sehingga penyaluran air pada saluran kampili masi tergolong efisiensi. Efisiensi pada saluran Induk Kampili sudah memenuhi melihat hasil grafik di atas, saluran Induk Irigasi Kampili sudah memenuhi kriteria efisiensi saluran karena, kehilangan air yang terjadi sepanjang saluran induk Kampili rata-rata 98\% sedangkan perkiraan efisiensi irigasi dalam (KP-01, 1986: 10 : 1) yaitu pada jaringan primer $90 \%$ dan untuk itu kita

Biasa lihat sebagaiman jaringan irigasi air.Tetapi kami selaku peneliti tidak bisa memastikan hal ini karena, selama penelitian ini dilaksanakan mungkin saja terjadi kesalahan pada proses perhitungan kecepatan aliran terutama pada lintasan pelampung. karena mengingat pelaksanaan pengukuran ini bertepatan dengan musim hujan yang sangat mempengaruhi kecepatan lintasan pelampung dan mengingat tingginya debit air yang membuat kecepatan pelampung bertambah. Penjelasan tentang garafik diatas sudah jelas alurnya.

Sehingga kami menghasilkan datadata tersebut sebagaimana yang sudah di lampirkan pada grafik 7 diatas yang menunjukkan saluran Induk Irigasi Kampili masi tergolong efisiensi.

Untuk grafik di atas menunjukkan hasil efisiensi dari pengukuran di lapangan dimana kehilangan air banyak terjadi pada saluran BL.1-BL.2yaitu 7,05 m²/dtk dan efisiensinya $94,14 \%$. Sedangkan kehilangan air paling kecil terjadi pada saluran BL.16-BL.17 yaitu 8,49 m³/dtk dan efisiensinya yaitu $89,94 \%$.

Sehingga penyaluran air pada saluran kampili masi tergolong efisiensi. Efisiensi pada saluran Induk Kampili sudah memenuhi melihat hasil grafik di atas, saluran Induk Irigasi Kampili sudah memenuhi kriteria efisiensi saluran karena, kehilangan air yang terjadi sepanjang saluran induk Kampili rata-rata $98 \%$ sedangkan perkiraan efisiensi irigasi dalam (KP-01, 1986: 10 : 1) yaitu pada jaringan primer 90\%. Tetapi kami selaku peneliti tidak bisa memastikan hal ini karena, selama penelitian ini dilaksanakan mungkin saja terjadi.

Melihat hasil analisis perhitungan pengukuran di lapangan, saluran Irigasi 
Kampili sudah memenuhi kriteria efisiensi saluran karena, kehilangan air yang terjadi sepanjang saluran induk Kampili rata-rata 97,30\% sedangkan perkiraan efisiensi irigasi dalam (KP-01, 1986: 10 : 1) yaitu pada jaringan primer $90 \%$.

Tetapi kami selaku peneliti tidak bisa memastikan hal ini karena, selama penelitian ini dilaksanakan mungkin saja terjadi kesalahan pada proses perhitungan kecepatan aliran terutama pada lintasan pelampung. karena mengingat pelaksanaan pengukuran ini bertepatan dengan musim hujan yang sangat. Dan dalam penelitian ini kita dapat simpulkan dalam berbagai aspek yang dilihat.

\section{PENUTUP}

\section{Kesimpulan}

1) Kehilangan air secara keseluruhan pada jaringan irigasi saluran primer rata-rata yaitu $3,99 \mathrm{~m}^{3} / \mathrm{dtk}$ Kehilangan air yang terjadi evaporasi sangat kecil, sehingga air yang hilang lebih disebabkan oleh faktor fisik saluran dengan kehilangan yang banyak terjadi pada saluran Primer 1, saluran primer

2) Efisiensi rata-rata secara keseluruhan pada jaringan irigasi saluran primer adalah $96,75 \%$.

\section{Saran}

1) Perlu dibuat perbaikan pada system pengelolaan air dan perbaikan fisik prasarana irigasi seperti: mengurangi kebocoran di sepanjang saluran, meminimalkan penguapan, menciptakan sistem irigasi yang andal, berkelanjutan dan diterima petani.

2) Untuk meningkat efisiensi penyaluran air sebaiknya pemerintah terkait meningkatkan kerjasama dengan pihak petani dalam hal tata cara pemakaian air yang baik.

3) Perlu dilakukan penelitian lanjutan untuk mengetahui optimalisasi pengelolaan Jaringan Irigasi Kampili.

\section{DAFTAR PUSTAKA}

Ambler, J.S., 1991. Irigasi di Indonesia Terhadap Kebutuhan Air Pada Tanaman Padi. LP3ES, Jakarta.

Ahmad Ansori, Anton Ariyanto, Syahroni. Efisiensi Kajian Efektivitas dan Efisiensi Jaringan Irigasi Terhadap Kebutuhan Air Pada Tanaman Padi.

Andriani Asarah Bancin, Dewi Sri Jayanti, T.Ferijal.Efisiensi Penyaluran Air Irigasi BKA Kn 16 Lam Raya Daerah Irigasi Krueng Aceh Jurnal RonaTeknik Pertanian, Volume 8, Nomor 1, April 2015.

Bunganaen, W,. 2011. Analisis Efisiensi dan kehilangan Air Pada Jaringan Utama Daerah Irigasi Air Sagu Jurnal Ilmiah Teknik Sipil Universitas Nusa Cendana, Vol 1, No 1.

Depertemen Pekerjaan Umum Direktorat Irigasi; "Standar Perencanaan 
Irigasi, Kriteria Perencanaan Irigasi (KP 01 - KP 07) “, Edisi Bahasa Indonesia. 1986.

Darmawangsa. SkripsiStudi Efisiensi Penyaluran Pemakaian Air Pada Jaringan Irigasi Pekkabatta Kabupaten Pinrang. Universitas Muhammadiyah Makassar.

Garg, Satnosh Kumar. 1981. Irrigation

Engineering and Hydraulick

Struktures. Khana Publisher. Naik

Sarak. Delhi.

Hansen, V.E., dan O. W. Israelsen. 1962. Dasar-dasar dan Praktek Irigasi. Edisi Keempat. Erlangga, Jakarta.

Hasan, M. 2005. Bangunan Irigasi Dukung Ketahanan Pangan. Majalah Air, Direktorat Jenderal Sumber Daya Air, Departemen Pekerjaan Umum. Jakarta.

Kartasapoetra, AG., dan M. Sutedjo 1994. Teknologi Pengairan Pertanian Irigasi, Bumi Aksara.

Ludiana,Wilhelmus,Tri M.W Sir.Evaluasi kinerja Jaringan Iirigasi Bendungan Tilong Kecamatan Kupang Tengah Kabupaten Kupang Jurnal Teknik Sipil, Volume 4, Nomor 1, April 2015.

M. Nurul Huda, Donny Harisuseno, Dwi Priyantoro. Kajian Sistem Pemberian Air Irigasi Sebagai Dasar Penyusunan Jadwal Rotasi Pada Daerah Irigasi Tumpang Kabupaten Malang Jurnal Teknik Pengairan, Volume 3, Nomor 2, Desember 2012.

Nur Zun Viqh, R. A. Bustomi Rosadi, Nugroho Haryono, Oktafri. M. Nurul Huda, Donny Harisuseno, Dwi Priyantoro. Evaluasi Kinerja
Jaringan Irigasi Tingkat Tersier Unit Pelaksanaan Teknis Pengairan Kota Metro Daerah Irigasi Kanpung Batanghari. Jurnal Teknik Pertanian, Volume 1, Nomor 21 Oktober 2012.

Partowijoto, 1984, Kapita Selekta Teknik Tanah dan Air. Majalah Dunia Insinyur, Jakarta.

Garg, Satnosh Kumar. 1981. Irrigation Engineering and Hydraulick Struktures. Khana Publisher. Naik Sarak. Delhi.

Hansen, V.E., dan O. W. Israelsen. 1962. Dasar-dasar dan Praktek Irigasi. Edisi Keempat. Erlangga, Jakarta.

Hasan, M. 2005. Bangunan Irigasi Dukung Ketahanan Pangan. Majalah Air,

Hasan, M. 2006. Bangunan Irigasi Dukung Ketahanan Pangan. Majalah Air, Direktorat Jenderal Sumber Daya Air, Departemen Pekerjaan Umum. Jakarta.

Hasan, M. 2005. Bangunan Irigasi Dukung Ketahanan Pangan. Majalah Air, Direktorat Jenderal Sumber Daya Air, Departemen Pekerjaan Umum. Jakarta.

Ramadhan, F., 2011, Kualitas Perairan Situ Gintung Tangerang Selatan, Jurnal Biogenesis, UIN Syarif Hidayatullah, Jakarta.

Ramadhan, F., 2011, Kualitas Perairan Situ Gintung Tangerang Selatan, Jurnal Biogenesis, UIN Syarif Hidayatullah, Jakarta.

Sudjarwadi. 1987. Dasar-Dasar Teknik Irigasi. Fakultas Teknik, UGM, Yogyakarta. 
Sudjarwadi. 1990. Teori dan Praktek Irigasi. Pusat Antar Universitas

Ilmu Teknik, UGM, Yogyakarta.

Soewarno, Hidrologi Operasional Jilid Ke Satu. PT. Citra Aditya Bakti : Bandung, 1991.

Soewarno, Hidrologi Operasional Jilid Ke Satu. PT. Citra Aditya Bakti : Bandung, 1990.

Triatmodjo, Bambang. Hidrologi Terapan. Bandung : Beta offset, 2008.
Yurizal Biahimo, David Rumambi, Daniel Ludon, Sandra Pakasi.Analisis Efisiensi Penyaluran Air Irigasi Dengan Sistem Informasi Geografis Bendungan Lomaya Kabupaten Bone Bolango Provinsi Gorontalo. Universitas Sam Ratulangi Manado.

Winpenny. J.T., 1997, Demand Management For Efficient and Aquitable Use,, Water Economic, Management and Demand, Oxfor. 